\title{
THE INFLUENCE OF LUBRICATION ON ELECTRICAL AND MECHANICAL PARAMETERS OF POTENTIOMETER RESISTIVE ELEMENT
}

\author{
S. NOWAK and B. HEROD \\ Research and Development Centre for Hybrid Microelectronics and Resistors "Unitra-Telpod" Kraków, Poland
}

(Received April 20, 1984; in final form September 18, 1984)

Fixed resistors are usually protected against environmental influences. For this aim, special lacquers are used. Much of the environmental qualities of such a resistor are directly related to its enclosure.

The resistive element of the potentiometer cannot be protected in the same way. The producers of quality potentiometers, especially thin film ones, designed an effective seal of their housing but it leads to an increase in production costs.

The first researches on thin film resistive elements for potentiometers, proved the major sensitivity of the unit to moisture cycling, because of high water chemisorption on the resistive element surface.

The chemisorption effect has the major influence on the temperature coefficient of resistance(TCR), because at a higher temperature, water desorption is occuring and the resistance of the film is undergoing a change.

However, the IEC Standard recommends dry out of resistive elements before TCR measurement; the potentiometer users feel that total resistance changes as a sum of temperature change and drying out change.

The present paper deals with trials to eliminate this disadvantage of thin film potentiometers by protection against moisture.

The protective coating should, because of its affinity to the resistive film, form durable protection against environmental influences, but should not increase the contact resistance of the wiper (CRV). Such a coating also should not increase the friction coefficient of the wiper.

To verify the hypothesis that polar lubricants can play a part in protective coating of thin film potentiometers, several different lubricants have been examined.

\section{THEORETICAL BASIS OF LUBRICATION}

Water molecules as components of a polar liquid are not distributed chaotically, but according to the physical phenomena, their electric dipoles are directed to the interior of the film. An elevation of temperature results in the evaporation of water molecules from the resistive film and consequently in changes in its electrical properties.

To verify the above hypothesis, the dessicated resistive film surface has been covered with a polar liquid, which could replace the water molecules. A great variety of chemical compounds have a polar molecular structure. Nevertheless, because of excessively low breakdown temperatures, not all of them could be used for this purpose.

One successful technique for protecting resistive films could be to apply some lubricants, so-called polar lubricants.

Typical polar lubricants are vegetable oil and animal fat. Their polarity is connected with bonds of fatty acid with high molecular weight alcohols. Usually, pure distillation products of petroleum do not contain functional groups which bestow polar capacity upon them. 


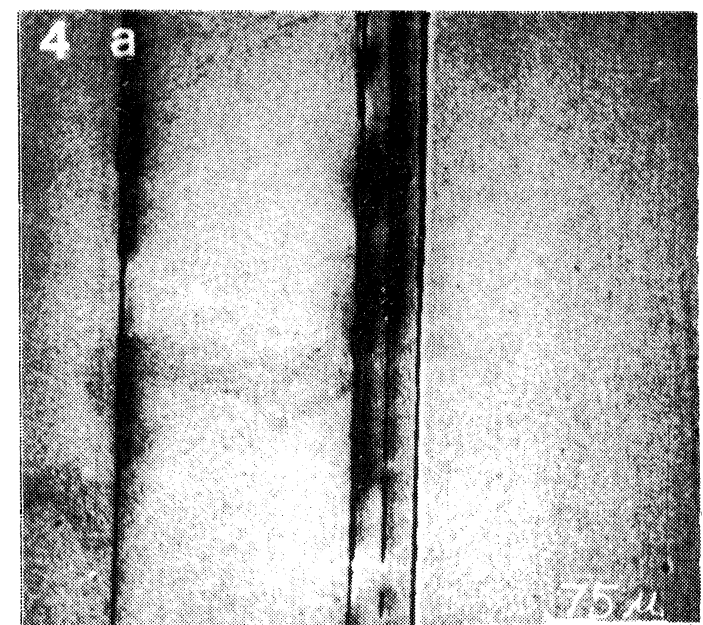

PHOTO 1 Mechanical failure of the resistive element after 0.5 million cycles. Target: Sb10 Sn 90 . Magnification: 55X

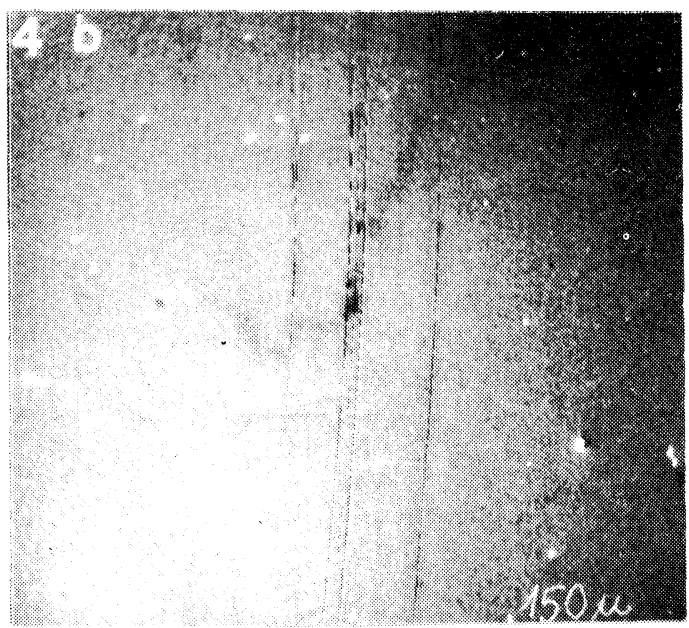

PHOTO 2 Mechanical failure of the resistive element after 0.5 million cycles. Target: Sb10 Sn 90 . Magnification: $220 \mathrm{X}$

To get the polarity, commonly suitable substances are added to distillation products. Often there are small amounts of natural fats or compounds of sulfur, chlorine or phosphorus.

\section{SAMPLE PREPARATION}

The samples were manufactured at the Research and Development Centre for Hybrid Microelectronics and Resistors "Unitra-Telpod" in Krakow by a sputtering technique on Corning 7059 substrate. The resistive film material was doped $\mathrm{SnO}_{2}$, because of its low cost and high sheet resistance.

All the resistive elements were kept during one hour in the dryer chamber at $150^{\circ} \mathrm{C}$ for desorption of water molecules from the resistive path. On the warm substrates, films 


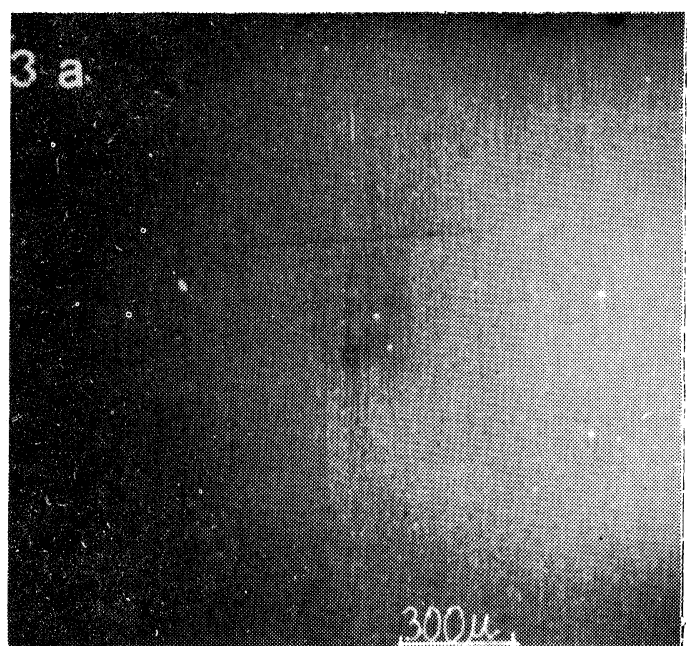

PHOTO 3 Mechanical failure of the resistive element after 0.5 million cycles. Target: Sb10 Sn 90. Magnification: $55 \mathrm{X}$

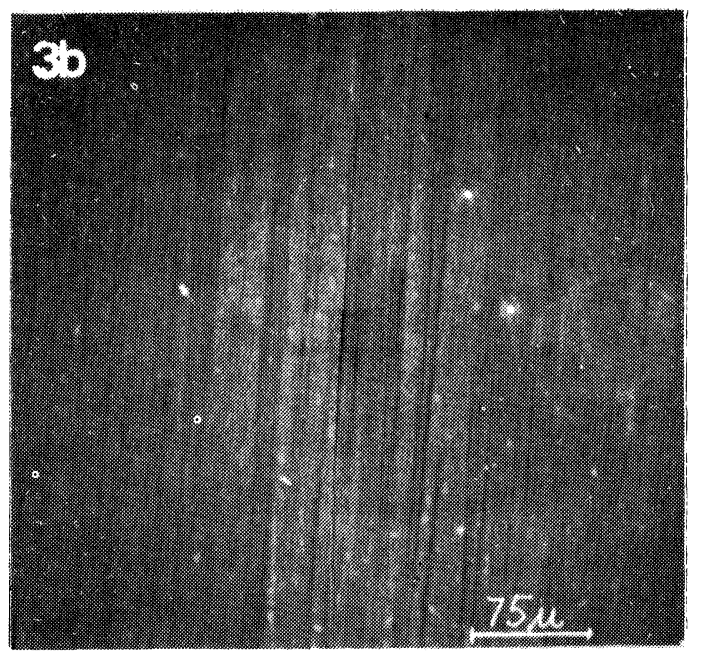

PнOTO 4 Mechanical failure of the resistive element after 0.5 million cycles. Target: Sb10 Sn 90 . Magnification: $220 \mathrm{X}$

of the following lubricants were put on: $\mathrm{Cu}-10$, Akorin PRM, Akorinol R, Aliten N, Liten EP-1, ZE-100, Wikson 30, Retinax A. The resistances of the resistive elements were measured at normal conditions. Variation about $42 \%$ relative to the initial resistance was found which suggests that water chemisorption has an important influence on the film resistance. So prepared samples were transferred to the testing laboratory for the purpose of measuring the TCR and moisture resistance. The tests were made following the Polish Standard Specification PN-74/T-04601.

\section{TESTING RESULTS}

Our investigation proved, that a correlation between the type of applied lubricant and the electrical parameters of thin film potentiometers does exist. 


\begin{tabular}{lcc}
\hline & \multicolumn{2}{c}{$\mathrm{TCR} / \mathrm{ppm} /{ }^{\circ} \mathrm{C}$} \\
\cline { 2 - 3 } Lubricant type & $\mathrm{t}=+125^{\circ} \mathrm{C}$ & $\mathrm{t}=+155^{\circ} \mathrm{C}$ \\
\hline Liten EP-1 & -135 & -196 \\
ZE-100 & -734 & -913 \\
Wikson-30 & -54 & -133 \\
Aliten N & -175 & -156 \\
Retinax A & -175 & -125 \\
Akorin PRM & -477 & -650 \\
Akorinol R & -354 & -556 \\
Cu-10 & -492 & +80 \\
\hline
\end{tabular}

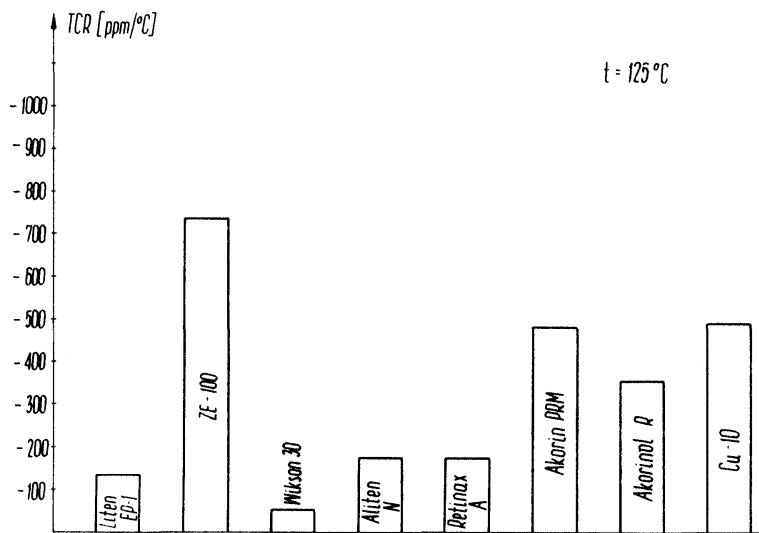

FIGURE 1 Temperature coefficient of resistance correlated with the applied lubricant

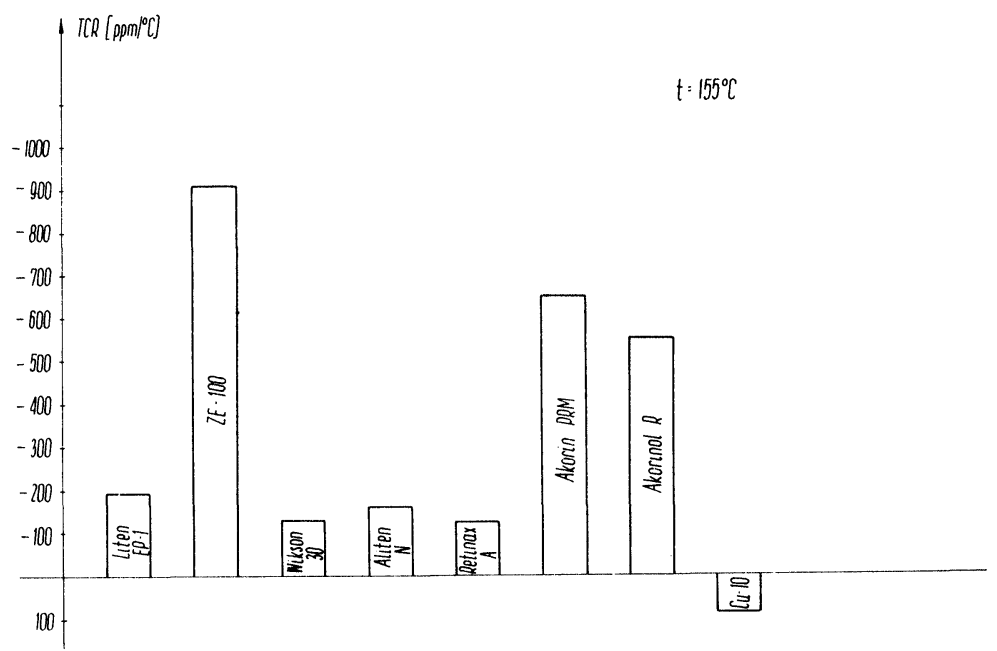

FIGURE 2 Temperature coefficient of resistance correlated with the applied lubricant

The arithmetic mean of TCR at temperatures $+125^{\circ} \mathrm{C}$ and $+155^{\circ} \mathrm{C}$ for every applied lubricant are inserted in Table 1 and graphical interdependence are shown in Figure 1 and Figure 2.

Similarly, the moisture cycling effect is correlated with the kind of protecting lubricants. The results of measurements are presented in Table II and Figure 3. 
TABLE II

\begin{tabular}{lcccc}
\hline Lubricant type & $96 \mathrm{~h}$ & $240 \mathrm{~h}$ & $504 \mathrm{~h}$ & $1344 \mathrm{~h}$ \\
\hline Liten EP-1 & 1.68 & 2.5 & 4.38 & 3.89 \\
ZE-100 & 0.8 & 1.25 & 1.34 & 3.78 \\
Wikson-30 & -3.1 & -3.16 & -2.78 & -1.28 \\
Aliten N & 1.2 & 1.96 & 1.42 & 2.53 \\
Akorin PRM & 2.5 & 3.52 & - & 13.0 \\
Akorinol R & 1.15 & 1.53 & - & 4.45 \\
Cu-10 & 0.57 & 0.64 & - & 8.17 \\
Unlubricated & 3.38 & 5.12 & 8.81 & - \\
\hline
\end{tabular}

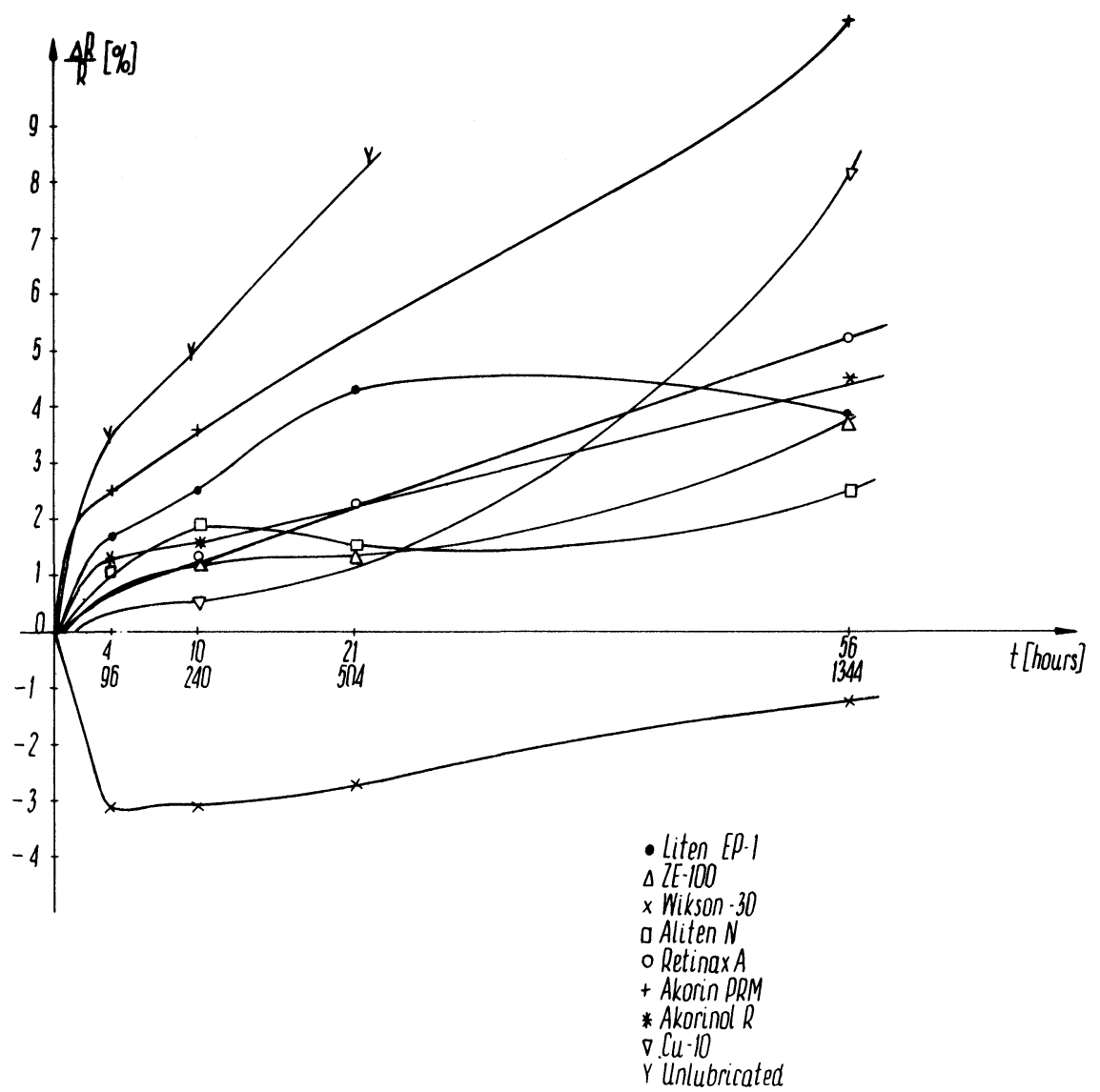

FIGURE 3 Moisture resistance of the thin film potentiometer correlated with the applied lubricant (relative humidity $95 \%$; temperature $55^{\circ} \mathrm{C}$ )

\section{ABRASION RESISTANCE}

The next investigation was to define the abrasion resistance of the lubricated thin film potentiometer. To carry out this experiment, the resistive elements were assembled into a housing and their control characteristic were plotted with a chart recorder. The chart for one potentiometer is shown in Fig. 4. After such examination, potentiometers were mounted in a rotational life fixture for simulation of the mechanical working condition of a potentiometer. Making use of this machine, the change of the potentiometer 


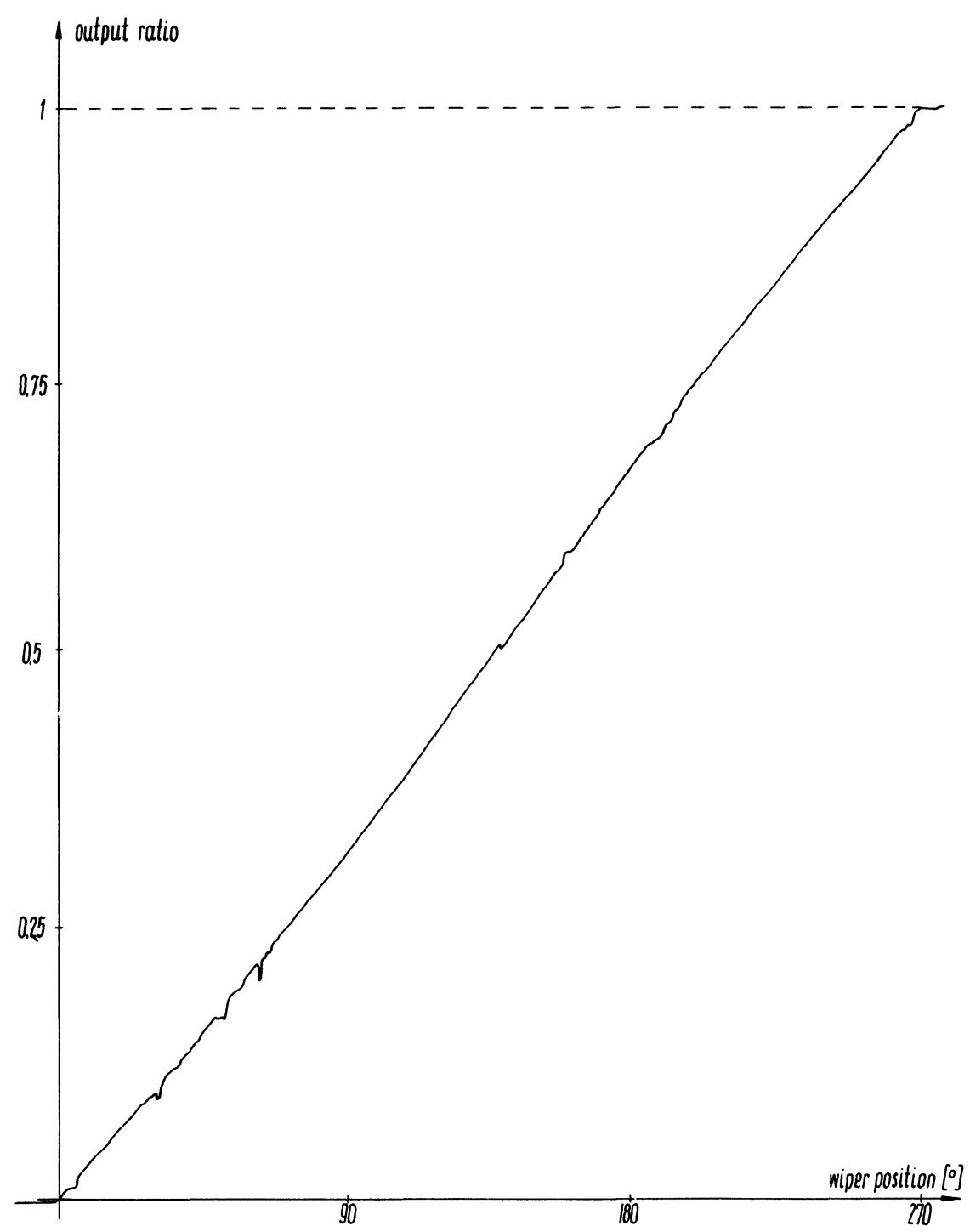

FIGURE 4 The control characteristic of potentiometer after 0.5 million cycles

resistance as a function of the number of wiper cycles was determined. It was found that those changes are dependent on the kind of resistive path as well as their doping. The mechanical failure of the resistive elements after 0.5 million cycles are shown on the scanning electron microscope photos. ${ }^{1,2,3,4}$ The control characteristic of the potentiometer after 0.5 million cycles of wiper action is shown on Fig. 5. From Fig. 4 and 5 , it is easy to find that the linearity is kept even after 0.5 million cycles.

\section{ANALYSIS OF THE RESULTS AND CONCLUSIONS}

Results of tests illustrated in Figures 1, 2, 3 prove that the type of protecting lubricant 


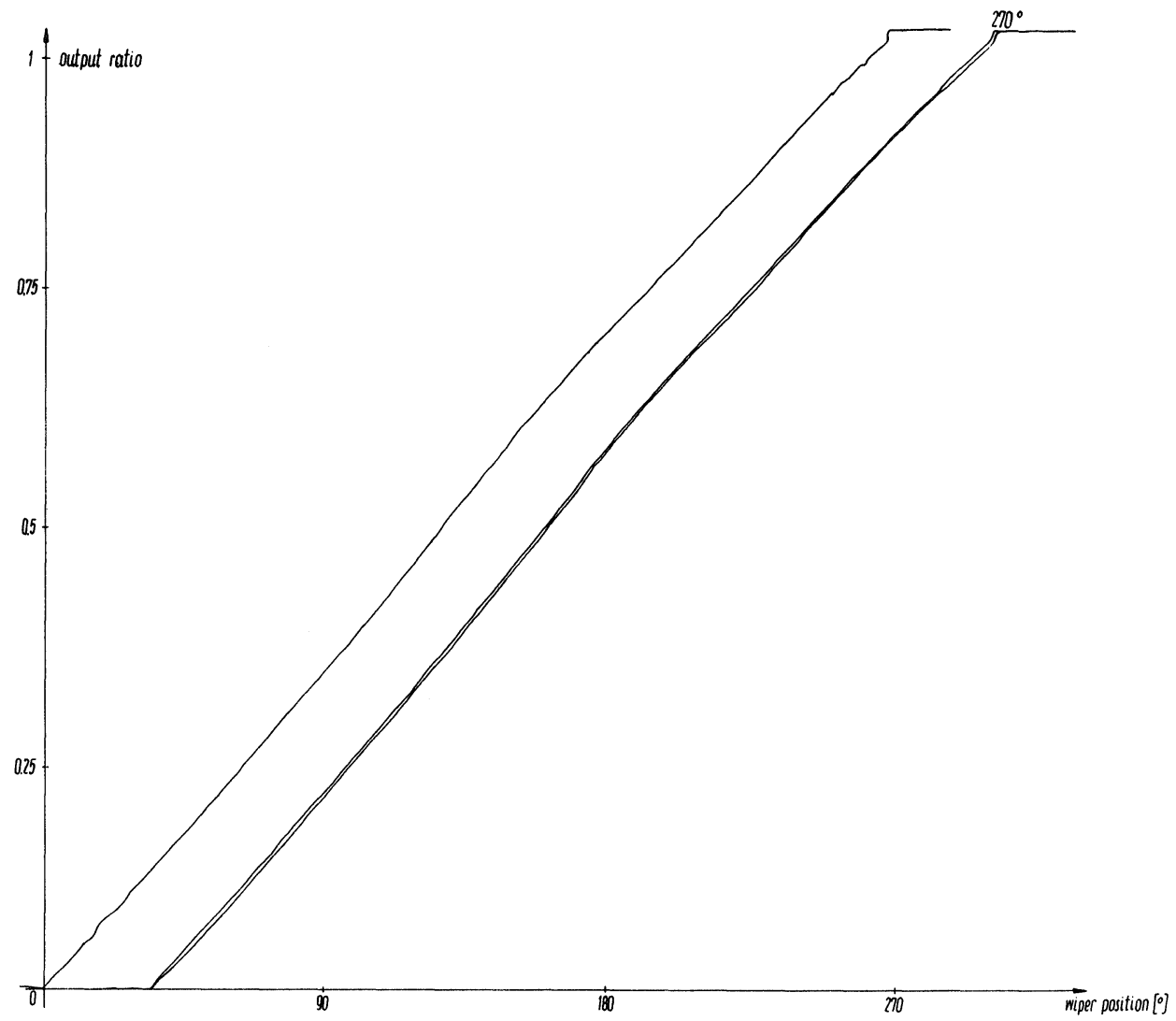

FIGURE 5 The control characteristic of potentiometer before wiper cycling

has an influence both on TCR and moisture resistance. These parameters are strictly connected.

The lubricant which assures sufficient moisture resistance gives also a low TCR. To compare results obtained by the authors during this investigation with Fig. 6[1], it is easy to find that ZE-100 lubricant does not protect the resistive path of a potentiometer

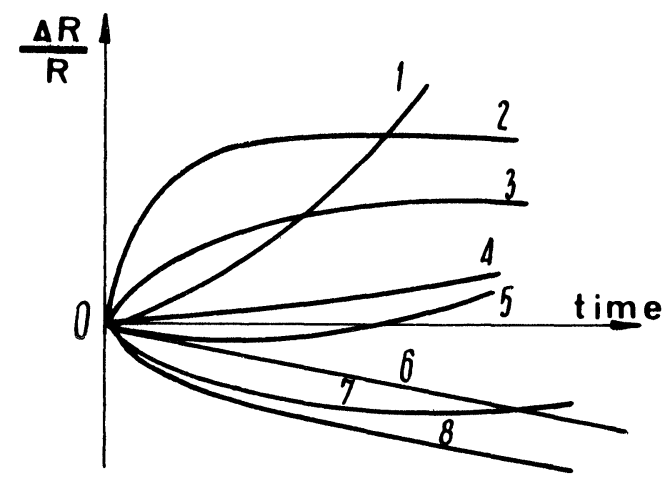

FIGURE 6 1- electrolysis, 2 - water absorption, 3 - gases absorption, 4 - oxidation, 5 - contact changes, 6 - crystallization, 7 - encapsulation changes, 8 - desorption of gases and liquids 
against humidity longer than 504 hours of the climatic stress. Also, $\mathrm{Cu}-10$ lubricant which contains fine grained copper, after 504 hours of climatic stress changes its chemical properties. The authors suppose that an electrolysis process or oxidation of the resistive path occurs because of the high catalysis capacity of copper.

From the examined lubricants, the best application properties were shown by Aliten $\mathrm{N}$, which contains aluminum monobasic stearate-benzoate and Wikson 30, which contains fine grained $\mathrm{MoS}_{2}[4]$.

At the present state of research work on thin film potentiometers, it is difficult to extend the results of experiments on all applied thin film materials and substrates. Such investigations will be carried out in the future. Their positive results create an alternative of choice between a cermet or carbon potentiometer which have the same or better electrical parameters due to better abrasion resistance.

\section{REFERENCES}

Galperin, B.S. Neprovolocnye soprotivlenia (Gosenergoizdat, Moskva 1958)

Todd, C.D. The Potentiometer Handbook (McGraw-Hill Book Company, USA, 1975).

Adamowicz, T. et al Handbuch der Elektronik (Franzis-Verlag Munchen, 1979).

Catalogue of Lubricants (Produced by "Naftochem", KAW, Krakow, 1980). 

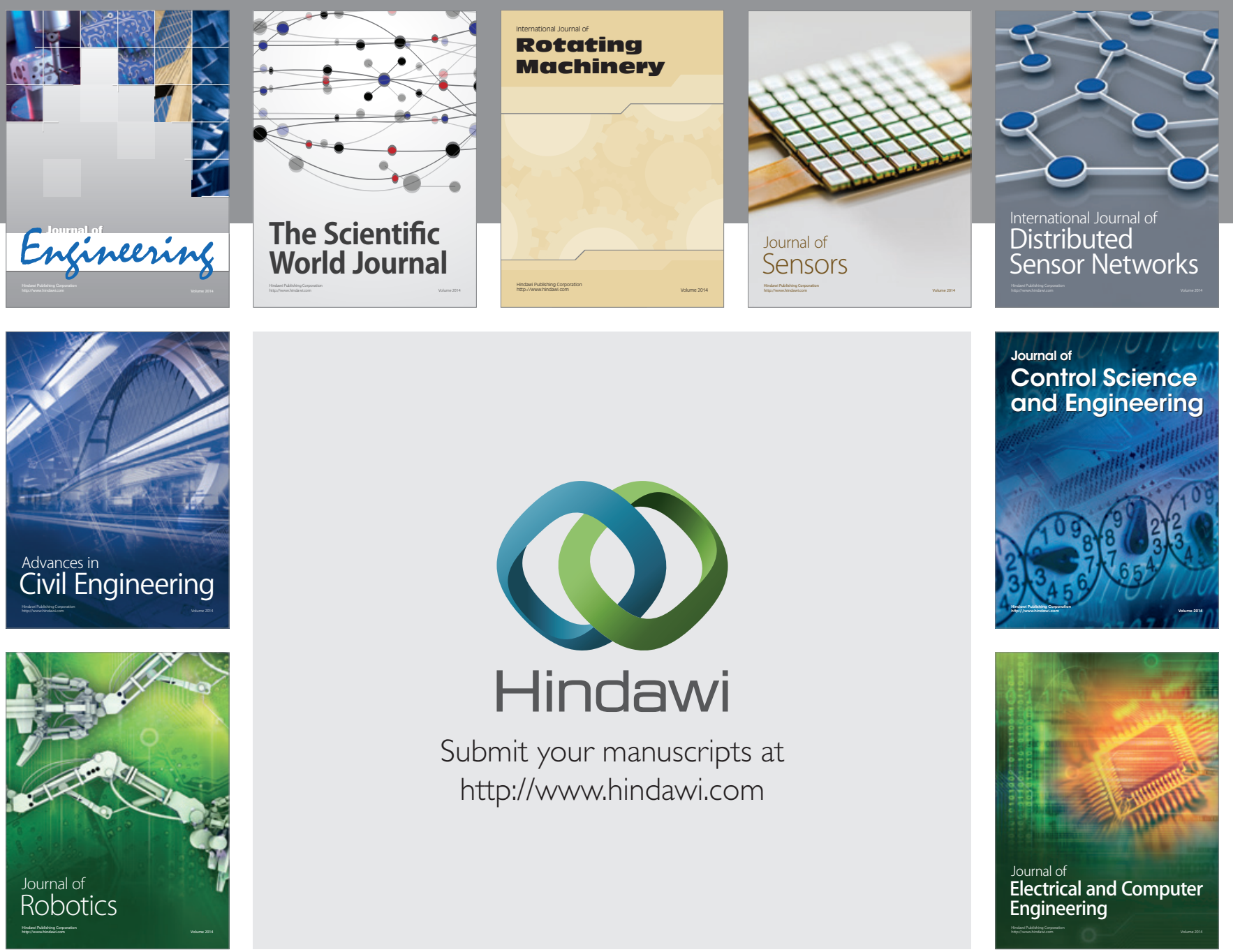

Submit your manuscripts at

http://www.hindawi.com
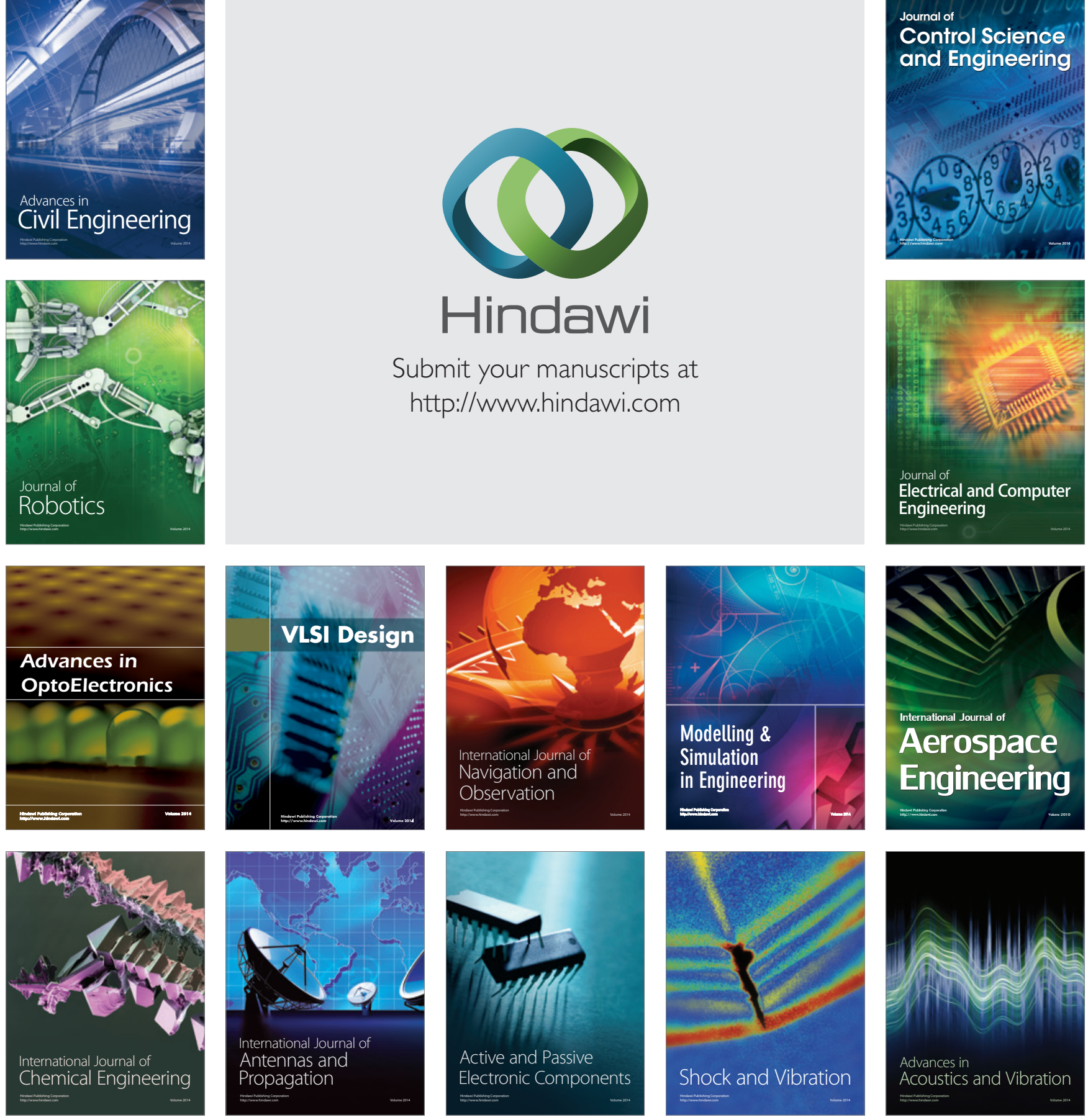